\title{
Impact and Perceived Benefits of a Problem-Based Learning Workshop for Continuing Education in Speech-Language Pathology: A Pilot Study
}

\author{
Megan S. Overby \\ Duquesne University, overbym@duq.edu \\ Heather L. Rusiewicz \\ Duquesne University, rusiewih@duq.edu \\ DOI: doi.org/10.30707/TLCSD2.10verby
}

Follow this and additional works at: https://ir.library.illinoisstate.edu/tlcsd

Part of the Other Rehabilitation and Therapy Commons

\author{
Recommended Citation \\ Overby, Megan S. and Rusiewicz, Heather L. (2018) "Impact and Perceived Benefits of a Problem-Based \\ Learning Workshop for Continuing Education in Speech-Language Pathology: A Pilot Study," Teaching and \\ Learning in Communication Sciences \& Disorders: Vol. 2: Iss. 1, Article 1. \\ DOI: doi.org/10.30707/TLCSD2.10verby \\ Available at: https://ir.library.illinoisstate.edu/tlcsd/vol2/iss1/1
}

This Scholarship of Teaching and Learning Research is brought to you for free and open access by ISU ReD: Research and eData. It has been accepted for inclusion in Teaching and Learning in Communication Sciences \& Disorders by an authorized editor of ISU ReD: Research and eData. For more information, please contact ISUReD@ilstu.edu. 


\title{
Impact and Perceived Benefits of a Problem-Based Learning Workshop for Continuing Education in Speech-Language Pathology: A Pilot Study
}

\author{
Abstract \\ Even though speech-language pathologists (SLPs) must participate in continuing education programs, \\ little is known about the effectiveness of these learning opportunities. This preliminary study provides \\ empirical assessment of the impact of a problem-based learning (PBL) CE activity on SLPs as perceived \\ by themselves and their Instructors. Twenty-five experienced SLPs participated in an intensive multi-day, \\ PBL workshop on childhood apraxia of speech. Significant differences in the SLPs' self-perceived clinical \\ efficacy between T1 and T2, as well as T2 and T3. At T3, Instructors rated the clinical efficacy of the SLPs \\ as "very good" to "excellent." Qualitatively, SLPs reported increased confidence, critical thinking, and \\ improved assessment/treatment skills following the training at T3. The SLPs also stated this workshop \\ stood apart from other CE models due to the intensity of learning, the professionals and mentors \\ available to them during and after the education experience, as well as instructional elements associated \\ with PBL such as a focus on small group case-based discussion. Study limitations, implications and \\ future directions are discussed.

\section{Keywords} \\ continuing education, problem-based learning, experiences, learning outcomes, childhood apraxia of \\ speech

\section{Cover Page Footnote} \\ We thank our colleagues (Sharon Gretz, David Hammer, Kathy Hennessy, Kathy Jakielski, and Ruth \\ Stoeckel) at the Childhood Apraxia of Speech Association of North America (CASANA) for their \\ collaboration and support in manuscript preparation. Thanks also go to Abigail Cummings, Nikki Hill, \\ Sarah Leech, Theresa Ptakowski, and Gabrielle Walsh for their assistance with data management. Lastly, \\ we express our gratitude to the speech-language pathologists who participated in this investigation and \\ to the reviewers/editors for their constructive comments.
}




\section{Introduction}

An important goal of continuing education (CE) programs in healthcare is to change the practice patterns of the participants, thereby improving clinical competency and subsequent patient care (Institute of Medicine, 2010). Incorporating problem-based learning (PBL) into CE programs has been shown to have a positive effect on the professional practice patterns of healthcare providers such as physicians (Davis et al., 1999; Fletcher, 2007; Mansouri \& Lockyer, 2007), but few studies have explored whether PBL CE programs alter the clinical practice patterns of speechlanguage pathologists (SLPs). Some studies have found an association between the extent of CE training and SLPs' self-perception of their efficacy in treating dysphagia (Fishbein, Flock, \& Benton, 2013; O’Donaghue \& Dean-Claytor, 2008) or voice disorders (Teten, DeVeney, \& Friehe, 2016), but investigators did not consider whether SLPs altered their treatment practice patterns because of such CE training. In this pilot investigation, we explored whether SLPs' self-perception of efficacy and treatment practice patterns were associated with PBL CE training in treatment of childhood apraxia of speech (CAS) and what aspects of the PBL CE experience SLPs considered most impactful to their learning.

Defining Problem-Based Learning (PBL). Howard Barrows first proposed PBL in the late 1960s within the context of medical student education at McMaster University. Barrows (1986) described PBL as learning that occurs during the process of understanding or resolving a problem, leading to improved comprehension and internalization of solutions to authentic clinical problems. Key characteristics of a PBL curriculum include it being student-centered, problembased, problem-solving, collaborative, authentic, and motivating (Barrows, 1998). However, researchers now believe there are different types of PBL (Albanese \& Mitchell, 1993), such as an educational philosophy facilitated by lectures and small group discussions of case-based problems (e.g., Fyrenius, Bergdahl \& Silen, 2005; Menahem \& Paget, 1990) or being an instructional method itself (Albanese \& Mitchell, 1993). Some researchers believe that PBL functions along a "continuum" with flexibility in its definition and delivery rather than operationalized along strict criteria (Harden \& Davis, 1998; Whitehill, Bridges, \& Chan, 2014). Nevertheless, common key components of PBL are activities that stimulate critical thinking skills, interaction in small groups, and participants' self-evaluation of their learning (Burda \& Hageman, 2015; Mok, Whitehill, \& Dodd, 2008; Prosser \& Sze, 2014).

In addition to these key characteristics, it is important to note that adult CE programs with a PBL focus contain aspects of several adult learning theories. For example, PBL CE programs are consistent with Houle's (1984) theory of adults as lifelong learners because these programs stimulate adults' internal motivation to 
learn and form enduring new learning perspectives (David, Dolmans, Patel, \& van der Vieuten, 1998; Institute of Medicine, 2010). Theoretical support is also found in self-directed learning theory which describes how adult learners are motivated (Knowles, 1975), as well as experiential learning theory which states that adults reflect on their active learning experience (Gibbs, 1988).

Thus, for the purpose of this pilot, we defined PBL in CE programs as critical thinking in small group interactions with opportunities for active self-evaluation of learning for motivated adult lifelong learners. This restricted definition of PBL was important for a small-scale pilot investigation, though limiting participants in this way introduced a bias (described in the limitations).

Effectiveness of PBL in CE programs. The impact of $\mathrm{CE}$ on the professional practice of healthcare professionals has been a topic of empirical study since the 1960s with 39 published systematic reviews in the field of medicine alone (Cervero \& Gaines, 2014). Studies suggest that healthcare providers who just passively attend didactic CE activities are not likely to change how they provide healthcare to their patients (Bjerr et al., 2015; Davis et al., 1999; Hess, Reed, Turco, Parboosingh, \& Bernstein, 2015; Institute of Medicine, 2010; Kitto et al., 2013; Leach \& Fletcher, 2008). However, physician medical practice patterns and patient care improve as the intensity (Forsetlund et al., 2009) and duration (i.e., 1, 2, or 3 hours) (Zeitz, 1999) of the CE program increase. For example, 38 physicians enrolled in a PBL CE program demonstrated $25 \%$ improvement on a Key Features Problems examination compared to those enrolled in a lecture based approach (Doucet, Purdy, Kaufman, \& Langille, 1998).

Although PBL CE programs appear to improve the practice patterns of physicians, there has been little attention paid to whether such programs might also alter the practice patterns of related healthcare professionals such as SLPs. One possible reason for this limited evidence may be that many CE programs for SLPs are didactic (e.g., lectures and seminars), provided in traditional CE settings such as auditoriums and classrooms, with wide variations in how participant learning is described. Activities that meet the definition of CE for SLPs may include workshops or conferences, self-paced readings, webinars, university courses, seminars, professional meetings, or other activities that maintain or develop an SLP's knowledge and/or clinical skills. Typically, improvement of the professional's knowledge and/or skills in these activities has been assumed by virtue of the participant's attendance, the CE learning objectives, or the participant's satisfactory performance on knowledge-based assessments, such as multiple-choice exams. To our knowledge, data on change in SLPs' clinical practice patterns after traditional or PBL CE activities are rarely collected. 
Effectiveness of Small-Group Tutorials in PBL. Although small-group tutorials are often a part of PBL CE healthcare programs, investigations have been limited to studying their effectiveness in changing physician practice patterns. In a metaanalysis of 14 studies of medical CE programs, one CE program that used a small group tutorial approach had no significant impact on physician performance, and outcomes from smaller ( $<10$ individuals) groups were no different than outcomes from larger ( $>20$ individuals) groups (Davis et al., 1999). However, Forsetlund et al. (2009) found that CE programs with a mix of didactic instruction and small groups were more effective in changing physician professional practice than small group CE programs alone. Although small group tutorials are also used in the teaching of pre-professional SLP students (Burda \& Hageman, 2015; Ho, Whitehill, \& Ciocca, 2014; McAllister et al., 2014), little is known about the value of such tutorials in CE training for SLP professionals.

Self-Efficacy and Clinical Competence. An important feature of clinical competence is the ability to accurately self-assess one's own clinical performance, strengths, and limitations (Gordon, 1991; Sargeant, Bruce \& Campbell, 2013). According to Bandura's Social Learning Theory, this skill is related to the social cognitive theory concept of "self-efficacy" (Bandura, 1977). Bray, Kehle, Lawless and Theodore (2003) define self-efficacy as "a measure of an individual's confidence regarding successful performance of particular behaviors" (p. 425). Understanding self-efficacy is important because self-perception can influence later performance, affecting an individual's ability to identify challenges and set goals, a construct known as the "expectancy hypothesis" (Rosenthal \& Jacobson, 1968). In short, self-efficacy is not simply feeling good about oneself, but is related to the self-confidence that brings potential for changed behavior patterns, such as improved clinical competence or performance.

Findings from studies examining the relationship between perceived self-efficacy and the clinical performance of healthcare providers are mixed. Multivariate general linear modeling revealed no association between perceptions of selfefficacy in cancer screening and performance of 146 medical students on standardized patient encounters (Hauer, Wilkerson, \& Teherani, 2008) nor was self-efficacy related to the performance of 113 medical students on an objective structured clinical exam (OSCE) (Mavis, 2001). However, in a study of 300 second year students in accredited physician assistant programs, self-efficacy was found to be a significant predictor of the students' clinical performance (Opacic, 2003).

Studies of the relationship between perceptions of self-efficacy and clinical performance are particularly lacking for SLPs engaged in CE programs. O'Donoghue and Dean-Claytor (2008) reported a negative correlation between the extent of post-graduate training and school-based SLPs' perceptions of selfefficacy in treating dysphagia; that is, SLPs with little training were more confident 
in treating dysphagia than those with more extensive CE training. However, the more hours participants acquired within the 2 year period prior to the study, the higher was their reported self-confidence in treating dysphagia. Nevertheless, the majority of participants surveyed in that investigation reported low-confidence levels. Different findings were reported in a study of school-based SLPs' selfefficacy perception in treating voice disorders (Teten et al., 2016). Participants reported being (on average) minimally to somewhat competent in treating voice disorders, with SLPs who had attended CE programs in the 5 years prior to the study feeling more competent than those who attended less recent CE programs. Differences in the content (i.e., dysphagia vs voice disorders) covered in the CE training could explain the disparate outcomes in SLPs' perceptions of self-efficacy, but additional study is needed to explicate these findings.

Framework for Determining Effectiveness of CE Programs. One means by which change in practice patterns and competency can be assessed is the OSCE. Based on Miller's (1990) 4-level pyramid of clinical skills, the OSCE is a multidimensional assessment in which the learner demonstrates that she "knows," "knows how," "shows how," and "does" competent assessment and treatment of patients. The areas of "knows" and "knows how" are typically evaluated via traditional written exams or projects, whereas "does" is tested by observing a student's actual clinical professional practice. This means that "shows how" could be addressed with the OSCE (Rushforth, 2007).

The OSCE consists of a series of stations, each containing an explicit case-based clinical task (providing key information, clinical assessment, interpretation of findings, patient education, and future management) presented in written form or as a simulation. The learner's performance at each station is evaluated by a clinical expert using an agreed-upon rubric to identify key clinical indicators the learner should exhibit. Typically, an additional written component assesses the learner's base knowledge. Although the OSCE reliability and validity requires additional study (Rushforth, 2007), health professionals nevertheless consider it the "gold standard" for assessing health professional clinical change (Bartfay, Rombough, Howse \& Leblanc, 2004).

Across healthcare professions, limitations of the OSCE have included student anxiety (Ryan, Stevenson, \& Hassell, 2007; Salinitri, O’Connell, Garwood, Lehr, \& Abdallah, 2012; Wanstall, 2010) and disagreement about grading criteria (Rushforth, 2007). The major drawback of the OSCE is the cost in identifying and providing qualified patients, faculty, and space resources (Patricio, Juliao, Fareleira, \& Carneiro, 2013). Regardless, practice with clinical skills (e.g., during formative evaluation) improves clinical performance on summative OSCE performance. Chisnall, Vince, Hall, and Tribe (2015) describe the positive predictive value $(92.5 \%)$ of formative OSCEs to predict whether second year 
medical students could pass a summative OSCE at the same station. Similarly, there was a significant correlation between 28 medical students' post-test OSCE scores at different stations and their summative OSCE examination, as well as, to their performance on their Bachelor of Medicine final exam. In their review of 1065 studies on the effectiveness of the OSCE (Patricio et al., 2013), the authors conclude the OSCE is feasible as both a formative or summative evaluation of medical students across 25 specialties, with a range of unique educational benefits cited and note the "valuable information" and "insight" that the OSCE can provide into student skill level.

In conclusion, a major goal of healthcare CE programs is to change the practice patterns of participants. Although some research findings imply that a PBL based CE program can be effective in altering the practice patterns of medical professionals such as physicians, gaps remain in our understanding of the outcomes of PBL CE programs for SLP professionals. Given that there are over 32,000 different CE opportunities offered annually with over 470,000 SLP participants (American Speech-Language-Hearing Association, 2016), empirical investigations of PBL CE programs in speech-language pathology are needed.

Purpose. The aim of this pilot study was to examine the utility of a PBL CE workshop specifically designed to change clinical practice patterns of SLPs in the area of childhood apraxia of speech (CAS). To address this aim, we designed an alternative OSCE (described below) to target the following questions: a) What is the impact of a PBL CE workshop on SLPs' perception of self-efficacy?; b) What is the impact of a PBL CE workshop on SLPs' performance on a summative activity as perceived by their Instructors?; and c) What experiences within such a $\mathrm{CE}$ program did the SLPs believe provided them the greatest benefit?

\section{Methods}

\section{Participants.}

Speech-language pathologists. Twenty-five female SLP participants (mean years of professional experience $=15.5 ; S D=8.06$ years; range $=6$ to 32 years) were enrolled in a CE activity called the Childhood Apraxia of Speech Intensive Training Institute ("CAS Boot Camp"), created and sponsored by the Childhood Apraxia of Speech Association of North America (CASANA). Following an extensive application and review process for 74 total applicants, CASANA selected these 25 participants for the Boot Camp based on applicants' clinical potential to reach "master clinician" status in assessing and treating CAS, a neurological speech sound disorder associated with motor speech planning and programming deficits (American Speech-Language-Hearing Association, 2007). CASANA's selection 
criteria were that participants: had at least 5 years of SLP experience (primarily with children); had attended previous CE programs on CAS; were able to discuss how previous CE programs informed their clinical practice; had the capacity to accept new clients with the disorder; demonstrated commitment to an ongoing relationship with CASANA; were willing to work as a local resource on CAS; were located in a geographical location lacking professionals trained in CAS; and demonstrated gaps in their knowledge of CAS assessment and treatment practices in their Boot Camp application. Gaps in an applicant's knowledge of CAS were identified by a review committee through a four-step subjective process considering: (1) the number and quality of workshops the applicant attended related to the assessment and treatment of motor speech disorders (particularly CAS); (2) the information found in the applicant's narrative describing their past and current experiences with CAS; (3) a written clinical appraisal and reflection of a CAS research study; and (4) an estimate of the amount of time the applicant spent in CAS intervention.

Thus, consistent with the definition of PBL CE programs that was adopted for the pilot investigation, these participants represented a specific subpopulation of SLPs. These were motivated adults who demonstrated a "life-long" (or least long-held) interest in learning about a topic and demonstrated a capacity to reflect upon their knowledge and skill level.

Instructors. The instructors for the pilot study were three SLPs (1 male, 2 female) who had been Instructors in the CE program since its inception in 2010. Each had at least 34 years of clinical experience as an SLP and an extensive background in assessing and treating CAS. Neither of the investigators functioned as an instructor.

Continuing Education Program. The CAS Boot Camp was held in Summer 2014 at Duquesne University in Pittsburgh, Pennsylvania. This CE experience had been refined from prior experiences and consisted of four consecutive full ( $8 \mathrm{am}-6 \mathrm{pm})$ days of instruction with approximately 30 hours of active learning activities. This intensive instructional format was necessary to minimize loss of income incurred by private practitioner participants. The first and last hour of the four-day program were spent in organizational and summative activities. The daily educational program consisted of alternating four small group tutorials with three large group meetings.

The characteristics of the workshop met our definition for a PBL CE program. First, for about $50 \%$ of the program, participants engaged in independent critical thinking related to simulated real-life cases (Appendix A). Second, the program used small group tutorials, each of which had a single instructor with eight or nine 
participants. These groups met for four hours each day. Finally, participants selfreflected on the learning process by writing four journal entries.

The emphasis on independent thinking through real-life case-based analysis was strong. Across the four days, participants and instructors discussed at least 15 clinical cases within both the small tutorials and the large groups. Discussions lasted $30-45$ minutes and were guided by an instructor's probing questions. In addition, within six months following the completion of the program, participants submitted to their instructor a four to six-page written case presentation on a client with CAS. The instructor provided limited feedback, and the participant had the opportunity to revise the written presentation. The instructor then rated the participant's skills and competencies on the presentation using the Alternative Objective Structured Clinical Exam (AOSCE) rubric (Appendix B) described below.

In order to attempt to insure that the feedback the instructor provided on the case presentation did not "teach to the AOSCE," the feedback provided was broad and minimal in context. Nevertheless, it is possible that the feedback provided inflated the ratings given by the instructors and did not represent the true skills of the participants. Ideally, the instructors should have rated the participants' AOSCE performance on the first submission of the case study, when no feedback had been given, but this did not occur due to time constraints.

Study Design. A mixed method quantitative and qualitative group research design was employed utilizing within-participants comparisons. Data were collected at three times: Time 1 (T1, the first hour of the CE program): Time 2 (T2, the last hour of the CE program); and Time 3, (T3, six months after the program's completion).

Quantitative Measures. The quantitative measure was an investigator-made 44item objective rubric (Alternative Objective Structured Clinical Exam (AOSCE); Appendix B). Items for a preliminary AOSCE came from instructors' suggestions; these were discussed and revised by the investigators and instructors until a final AOSCE was agreed upon by all. The AOSCE covered skills in evaluation of CAS (19 items), intervention of CAS (13 items), and integration with broader skills (12 items). Instructors addressed scoring fidelity of the AOSCE through email and phone discussions. Instructors reached consensus regarding interpretation of each AOSCE item and discussed these interpretations with the investigators.

The AOSCE differed from a traditional OSCE in that instructors did not directly assess participants' clinical skills at stations. Instead, instructors used the AOSCE 
to rate a participant's clinical skills and competencies inferred from the written case presentation; and SLPs used it to self-evaluate their clinical competence as described in the Procedures.

AOSCE reliability. A post-hoc informal measure of inter-rater reliability for consistency of responses revealed no significant differences at T3 between the instructors and SLPs across all AOSCE items $(\mathrm{t}=-.15, \mathrm{p}=.88)$. Nor were there significant differences at T3 between instructor and SLP responses for the subdomains of assessment $(\mathrm{t}=.45, \mathrm{p}=.65)$, treatment $(\mathrm{t}=.13, \mathrm{p}=.89)$, or integration $(\mathrm{t}=.66, \mathrm{p}=.52)$. Although the SLPs were rating their own self-efficacy and thus could be biased in their interpretation of individual AOSCE items, the lack of statistical significance between the instructor and SLP ratings implies a degree of concordance between the two groups and that the AOSCE had some degree of reliability. However, no other measures of reliability of the AOSCE were obtained.

Qualitative Measures. Qualitative information regarding the benefits and experiences related to this CE workshop was obtained from (1) a semi-structured focus group interview at $\mathrm{T} 2$ and (2) an eight-item questionnaire sent via surveymonkey.com at T3. Questions from both measures are shown in Table 1.

Table 1. Questions on Two Qualitative Measures

\begin{tabular}{|c|c|}
\hline Focus group interview at $\mathrm{T} 2$ & Survey questionnaire at T3 \\
\hline $\begin{array}{l}\text { Compare this training to a previous training } \\
\text { experience. How was the instruction } \\
\text { approach the same or different? What is an } \\
\text { advantage of those differences? What is a } \\
\text { disadvantage of those differences? }\end{array}$ & $\begin{array}{l}\text { Compare this training to a previous training } \\
\text { experience. How was the instruction } \\
\text { approach the same or different? }\end{array}$ \\
\hline $\begin{array}{l}\text { Describe your experience and perceptions of } \\
\text { the assessment and feedback procedures } \\
\text { during this training program. }\end{array}$ & $\begin{array}{l}\text { Describe your experience and perceptions } \\
\text { of the assessment and feedback procedures } \\
\text { of this training program. }\end{array}$ \\
\hline $\begin{array}{l}\text { How would you describe change in your } \\
\text { clinical reasoning following this experience? }\end{array}$ & $\begin{array}{l}\text { How would you describe change in your } \\
\text { clinical reasoning following this } \\
\text { experience? }\end{array}$ \\
\hline $\begin{array}{l}\text { What suggestions for improvement would } \\
\text { you make? }\end{array}$ & $\begin{array}{l}\text { What suggestions for improvement would } \\
\text { you make? }\end{array}$ \\
\hline \multirow[t]{2}{*}{$\begin{array}{l}\text { What were the most helpful aspects of the } \\
\text { experience of "Boot Camp"? }\end{array}$} & $\begin{array}{l}\text { What was the most helpful aspect(s) of the } \\
\text { experience? }\end{array}$ \\
\hline & $\begin{array}{l}\text { In what ways do you feel empowered to } \\
\text { serve not only your clients and their }\end{array}$ \\
\hline
\end{tabular}


What are your perceptions about the effectiveness of learning about clinical scenarios in the absence of actual clients?

Describe your experience of working with your mentor(s).

Describe your experience of learning and working closely with your fellow members of your group and the training program. families, but the larger community and the profession of speech-language pathology as a result of this experience?

Describe a recent clinical experience that was impacted by your participation in "Boot Camp".

In what ways has your participation in "Boot Camp" helped you to continue to learn and grow as a professional in the past six months?

Procedures. In the first hour of the workshop (T1), the investigators completed all informed consent procedures in accordance with the Duquesne University Institutional Review Board. All workshop attendees and the three instructors independently volunteered to participate; thus, all involved in the CE program were aware of the research study and its purpose. However, throughout the study, data from SLPs and instructors were available only to the investigators to minimize participant bias.

After signing the informed consent, participating SLPs $(n=25)$ were given the AOSCE and asked to rate their self-efficacy in the assessment, treatment, and integration/education of CAS $(1=$ not at confident; $2=$ somewhat confident; $3=$ confident; $4=$ very confident; $5=$ extremely confident). In the last hour of the workshop (T2), the investigators asked the participants to complete the AOSCE again and also conducted the focus group interviews $(n=12)$. All interviews were audio-recorded and transcribed word-for-word for analysis.

At T3 (six months after the completion of the workshop), the SLPs $(n=19)$ completed the AOSCE via surveymonkey.com. Also at T3, each instructor assessed the quality of the final written case study submitted by each participant assigned to $\mathrm{him} /$ her and used the AOSCE to reflect his/her perception of that participant's skills and competencies. Although our original intent was that the instructors use the AOSCE to assess the participants' clinical competence at all three time points, they completed it only at $\mathrm{T} 3$ due to time constraints.

Quantitative data relative to the first and second questions were analyzed with statistical analysis. To address the third question, two graduate students trained by the second author in content analysis examined responses from the survey questionnaires and transcripts from the interviews for themes and patterns 
(Auerbach \& Silverstein, 2003). One student coded responses for thought units and identified emergent themes/subthemes. All one-word responses $(n=6)$ were excluded (e.g., "Long."). The second graduate student, given a list of themes/subthemes, checked that the "themes appropriately encompassed the codes" (McCormack, McLeod, McAllister \& Harrison, 2010, p. 383). Agreement between the two graduate students across themes was high (89.4\%); consensus was reached for disagreements via discussion among the two students and the second author.

\section{Results}

Question 1: What is the impact of a PBL CE workshop on SLPs' perception of self-efficacy? Analysis of SLPs' perceptions of their self-efficacy according to the AOSCE (Table 2) shows a significant increase for all 44 items between T1 and $\mathrm{T} 2(t=3.85, p<.001), \mathrm{T} 2$ and T3 $(t=3.39, p<.01)$, and T1 and T3 $(t=9.71, p<$ $.001)$. At T1 and T2, means for the AOSCE assessment items (3.37, 3.79; respectively) were lower than that for treatment (3.46, 3.96; respectively) or integration $(3.83,4.20$; respectively). Across all time points, SLPs were generally very confident in their clinical skills, scoring only four items at or below $3.0(3=$ confident). These four low scores appeared at $\mathrm{T} 1$ and three of them fell within the assessment category.

Cohen's effect size values suggested a moderate to high practical significance for comparisons between T1 and T2 across all SLP responses $(d=.68)$, as well as the three subdomains of assessment $(d=.62)$, treatment $(d=.74)$, and integration $(d=$ .59). Likewise, Cohen's effect size values suggested high practical significance for comparisons between T1 and T3 across all SLP responses $(d=1.69)$, as well as the three subdomains of assessment $(d=1.50)$, treatment $(d=1.67)$, and integration $(d$ $=1.27$ ).

Table 2. SLPs' Alternative Objective Structured Clinical Examination Means and Standard Deviations

\begin{tabular}{cccccccccccc}
\hline & \multicolumn{2}{c}{$\mathrm{T} 1$} & \multicolumn{1}{c}{$\mathrm{T} 2$} & \multicolumn{3}{c}{$\mathrm{T} 3$} \\
\hline Total & $\mathrm{A}$ & $\mathrm{T}$ & $\mathrm{I}$ & Total & $\mathrm{A}$ & $\mathrm{T}$ & $\mathrm{I}$ & Total & $\mathrm{A}$ & $\mathrm{T}$ & $\mathrm{I}$ \\
\hline 3.53 & 3.37 & 3.46 & 3.83 & 3.95 & 3.79 & 3.96 & 4.20 & 4.40 & 4.45 & 4.35 & 4.58 \\
$(0.55)$ & $(0.58)$ & $(0.63)$ & $(0.60)$ & $(0.68)$ & $(0.78)$ & $(0.72)$ & $(0.68)$ & $(1.02)$ & $(0.86)$ & $(0.46)$ & $(0.41)$ \\
\hline
\end{tabular}

Note. $\mathrm{T} 1=$ workshop first hour; $\mathrm{T} 2=$ workshop final hour; $\mathrm{T} 3=6$ months after workshop; $\mathrm{A}=$ AOSCE assessment items; $\mathrm{T}=\mathrm{AOSCE}$ treatment items; $\mathrm{I}=\mathrm{AOSCE}$ integration items. 
Question 2: What is the impact of a PBL CE workshop on SLPs' performance following a summative activity-as perceived by their Instructors? To address this question, instructors' AOSCE scores about participants' clinical competence at T3 were combined to obtain an instructor AOSCE overall mean, as well as instructor AOSCE means for assessment, treatment, and integration. All of these means (overall $=4.44(0.46)$; assessment $=4.35(0.55)$; treatment $=4.37(0.50)$; integration $=4.67(0.41)$ ) fell between a Likert rating of 4 ("very good") and 5 ("excellent"). Though there was no significant difference between instructors" AOSCE ratings of SLPs' assessment and treatment competence $(t=.30, p=.77)$, the instructors' ratings of SLPs' skills in integration were significantly higher than they were in either assessment $(t=4.17, p<.001)$ or treatment $(t=4.44, p<.001)$. Thus, according to the instructors, the workshop facilitated SLPs' skills in all areas, but had a greater impact on integration (i.e., collaborative skills, general knowledge base, etc.) than on assessment or treatment.

Question 3: What experiences within this CE program do SLPs report provided the greatest benefit? To answer this question, 123 discrete responses (60 obtained at T2 and 63 at T3) were examined. Two major constructs appeared: (1) experiences related to the learning process (Table 3) and (2) SLPs' perceived impact of training on self-efficacy.

As seen in Table 3, eight themes described Construct 1 (perceived values and benefits of the workshop): (1) peers (24 responses); (2) assigned mentors (22 responses); (3) support after conclusion of the workshop (21 responses); (4) development of critical thinking skills (19 responses); (5) discussionbased/interactive learning (14 responses); (6) a supportive, respectful milieu (11 responses); (7) extended support and community (8 responses); and (8) intensity of learning process (6 responses).

Four themes emerged for Construct 2 (Table 4), SLPs' perception of the workshop on their self-efficacy: (1) increased confidence and leadership (13 responses); (2) impact on therapy practices (9 responses); (3) impact on assessment practices ( 8 responses); and (4) impact on interactions with families (5 responses).

Table 3. Themes and examples for Construct 1

\begin{tabular}{ll}
\hline Construct 1: Experiences Related to the Learning Process \\
\hline Theme & Example Responses \\
\hline Peers & "I learned from everybody here, not just the experts. That \\
& was so fulfilling." \\
\hline
\end{tabular}


- 'Oftentimes you still feel like you're on an island, and here, we're leaving with a network, a support base."

- "The learning continues through their comments, but also from the other previous boot campers. I think-wow these SLPs are amazing."

Mentors $\quad$ " "...about how passionate and how good they are as teachers. I think we've all been to a training where the instructor doesn't give the information in a way that it can be learned. I felt that these guys understand teaching us through discussion, critical thinking, demonstration, etc."

- "I think that it was nice to have somebody you knew was 'your person' and you could go and they were 'your person' and they had your back."

Support after - "I really enjoyed the case study project at the end. It was Boot Camp great to receive feedback on how I was doing as we don't get that very often in this field once you are out there working."

- "I am constantly amazed by the discussions on the Yahoo group. This keeps me motivated to actively work on projects."

Critical - "It was great to access a higher level of thinking, to dig deep thinking in assessment or therapy techniques."

- "It has pushed me to think more critically, ask more questions of the parents, and ask more questions of myself."

- "I have always analyzed what was working in therapy, but now I do it even more so that I am providing the most beneficial therapy I can."

Discussion and - "The rich conversations and discussions, the experiences interaction that others brought, the sharing of information for an extended time period..."

- "The approach at Boot Camp was much more beneficial since there were many discussions which allowed me to learn the material in different ways. In comparison to a lecture, you get more in-depth work with a topic when you can discuss and work through the information."

Supportive, encouraging milieu
- "It was far superior to any other training because of the open approach of the instruction/instructors."

- 'Having instructors that weren't afraid to say 'I don't know.' Instructors that don't all do the same thing, which made us 
feel better about not doing the same thing, but still get the job done. There's no one right answer."

\begin{tabular}{lll}
\hline Extended & - & "I will say, since I have been to a different boot camp, you \\
support and & are doing an excellent job to keep us informed and to keep \\
community & us plugged in afterwards. That was one thing that my other \\
training that was intense like this did not have....as far as \\
professionally staying in touch and continuing to learn, that \\
was a short fall." \\
- "Boot Camp not only increased my knowledge level for \\
evaluation and intervention, but it also gave me more \\
resources to use and fellow therapists for support." \\
-
\end{tabular}

Table 4. Themes and examples for Construct 2

\begin{tabular}{|c|c|}
\hline Theme & Example Responses \\
\hline $\begin{array}{l}\text { Increased } \\
\text { confidence/ } \\
\text { Leadership }\end{array}$ & $\begin{array}{l}\text { - "To feel like you're the expert in your geographical area, I feel } \\
\text { like I'm the expert of CAS in my little area." } \\
\text { - "Since Boot Camp I have done } 3 \text { presentations for colleagues." }\end{array}$ \\
\hline $\begin{array}{l}\text { Impact on therapy } \\
\text { skills }\end{array}$ & $\begin{array}{l}\text { - "I totally changed the way I was going to approach her therapy. } \\
\text { I had only seen her twice before, and it just gave me a different } \\
\text { mindset for her." } \\
\text { - "My treatment has been most immediately impacted." }\end{array}$ \\
\hline $\begin{array}{l}\text { Impact on } \\
\text { assessment skills }\end{array}$ & $\begin{array}{l}\text { - "I recently evaluated a new client for possible CAS. My } \\
\text { experience with Boot Camp and the case study altered my } \\
\text { approach." } \\
\text { "I am more comfortable making a differential diagnosis } \\
\text { earlier." }\end{array}$ \\
\hline $\begin{array}{l}\text { Impact on family } \\
\text { interactions }\end{array}$ & $\begin{array}{l}\text { - "In speaking with a mother of a child with CAS, I was more } \\
\text { aware of the counseling aspect to what was needed since she } \\
\text { was struggling with the idea that her son had CAS." }\end{array}$ \\
\hline
\end{tabular}

\section{Discussion}

Little is known about the effectiveness of PBL CE programs in changing clinical practice patterns of SLP professionals. In this pilot study, we selected a small group 
of SLPs who were motivated and committed to learning about a disorder area (CAS), and explored the effectiveness of a PBL CE program on the SLPs' perception of self-efficacy, their performance on a summative activity at the end of the workshop, and what aspects of the workshop the SLPs considered most impactful to their learning.

The finding that SLPs' perceptions of their clinical self-efficacy improved between the beginning (T1) and the end (T3) of the workshop implies that participants believed the workshop improved their clinical practice pattern. This is consistent with Bandura's (1977) contention that mastery experiences (with feasible yet challenging goals) and identifying with a mentor are essential for self-efficacy.

SLPs consistently rated self-efficacy in assessment lowest on the AOSCEs. One participant summarized this difficulty with assessment as follows: "As far as knowing what to do specifically in my assessment, to say 'Yes, it is apraxia', I still think there is that gray area...but I think that that is that gray area that we are all experiencing across our whole profession when it comes to childhood apraxia". Reasons for participants' comparative difficulty with assessment include the possibilities that: assessment of any communication disorder is particularly difficult compared to other aspects of clinical work; additional workshop time was needed to teach assessment practices related to the disorder studied (CAS); or the participants needed processing time beyond the workshop to fully appreciate the assessment tools and practices discussed.

However, because perception of self-efficacy is not a direct measure of SLPs' clinical performance, any potential clinical practice change is better understood within the context of instructors' ratings of SLPs' clinical performance on a summative activity at T3, six months after the completion of the workshop. At that time, instructors rated the SLPs' clinical skills as "very good" to "excellent," suggesting that the workshop had a positive influence on the participants' clinical practice patterns. However, because instructors did not rate the SLPs' clinical skills at the beginning of the workshop (T1), change between T1 and T3 can only be inferred. Although it is reasonable to infer that SLPs were not as skilled at T1 as they were at $\mathrm{T} 3$ since participant selection criteria at $\mathrm{T} 1$ required gaps in participants' knowledge of assessment and treatment practices, it is important to recognize that these gaps were not identified by objective measures, but by subjective evaluation of the application materials submitted.

According to the instructors, the most significant change in SLPs' clinical practice was the quality with which the participants used newly acquired knowledge and skills, such as, broad knowledge, family education, and collaboration with others (see Integration in Appendix B). This suggests that PBL CE programs for SLPs 
have the capacity not only to improve specific skills (i.e., assessment and treatment of a particular disorder), but can change how SLPs interact with the public and other professionals.

The qualitative analysis revealed experiences that SLPs perceived as beneficial and, possibly, associated with their new clinical practice patterns. Although some participants made negative comments about the time requirements and intensity of the $\mathrm{CE}$ program, noteworthy facets of the learning experience emerged in the themes. These included close relationships with the instructors, creation of community, learning from peers, discussion-based learning, emphasis on critical thinking, and the availability of a peer community in the form of an online discussion group following the learning experience. The preponderance of positive characteristics implies that SLPs may value and seek out intense PBL focused CE workshops and offers some important considerations when developing such programs for SLPs.

Limitations. There are significant limitations to consider when appraising the results of this investigation. Linking participation in $\mathrm{CE}$ activities to clinical practice change is challenging because multiple variables that could affect clinical practice (e.g., internal states such as motivation, effects from past CE experiences) cannot be easily controlled (Institute of Medicine, 2010). Because the sample size was small and participants had been selected for their potential to reach "master clinician" status, results may not be generalizable to the larger SLP population. Furthermore, we explored a single PBL CE workshop experience with limited data (that is, at T1, instructors did not assess the participants' skills) and at T3, the SLPs discussed and/or wrote about clinical cases as opposed to being observed working directly with clients. It is also possible that SLPs and instructors inadvertently inflated their responses due to the perception that SLPs must have increased their competence and efficacy given the resources involved with such a specialized learning experience. Finally, quantitative measures of validity and reliability of the AOSCE are lacking, although scoring fidelity was discussed among the instructors before and during the workshop.

Future studies of the impact of PBL CE programs on the clinical practice patterns of SLPs should address these limitations. For example, to control variables associated with clinical practice change, we suggest that investigators collect information about participants' views and attitudes towards past CE experiences, as well as measuring participants' motivation (perhaps through a Likert scale) for attending the CE program being investigated. Future studies should also include the use of more frequent objective measures of clinical knowledge and skills obtained through a traditional or alternative OSCE. Data collection with these measures 
would require a significant time commitment by the instructors of the PBL CE program, perhaps necessitating an instructor:participant ratio lower than the 1:8 used in our pilot. Instructor inter-rater reliability for the traditional or alternative OSCE used is recommended. Replication studies should include larger sample sizes, if possible.

Conclusions. Despite the limitations of this pilot investigation, there are some preliminary, cautious conclusions that can be made. Because findings indicate that both SLPs and instructors believe PBL CE workshops can change the clinical practice patterns of workshop participants, it is possible that SLPs can, and possibly should, shift away from the archetypal CE model of short, didactic lecture-based workshops and seek activities that require consolidated time and experiential learning. Intense interactive learning experiences, such as $\mathrm{CE}$ workshops, may be best constructed by concentrating on a focused topic in a PBL pedagogical context, particularly if those experiences include the creation of a close community of learners who have close relationships with the instructor(s).

Given the number of SLPs who annually engage in CE activities, additional research is needed to systematically and empirically assess the impact of $\mathrm{CE}$ learning experiences on participants' self-efficacy and subsequent clinical practice patterns. Future research directions could include empirical assessment of PBL CE workshop formats other than the intense 3-day experience described here, as well as direct observation and quantification of clinical practice change associated with various types of CE learning experiences.

\section{References}

Albanese, M., \& Mitchell, S. (1993). Problem-based learning: A review of literature on its outcomes and implementation issues. Academic Medicine, 68(1), 5281.

American Speech-Language-Hearing Association. (2007). Childhood apraxia of speech. Retrieved from http://www.asha.org/policy.

American Speech-Language-Hearing Association. (2016). Continuing education board manual. Retrieved from http://www.asha.org/CE/forproviders/admin/ceb-manual/.

Auerbach, C., \& Silverstein L. B. (2003). Qualitative data: An introduction to coding and analysis. New York, NY: University Press. 
Bandura, A. (1977). Self-efficacy: toward a unifying theory of behavioral change. Psychological Review, 84(2), 191.

Barrows, H.S. (1986). A taxonomy of problem-based learning methods. Medical Education, 20, 481-486.

Barrows, H. S. (1998). The essentials of problem-based learning. Journal of Dental Education, 62, 630-633.

Bartfay, W., Rombough, R., Howse, E., \& Leblanc, R. (2004). The OSCE approach in nursing education. Canadian Nurse, 100(3), 18-23.

Bjerr, L. M., Paterson, N. R., McGowan, J., Hogg, W., Campbell, C., Viner, G., \& Archibald, D. (2015). Do continuing medical education (CME) events cover the content physicians want to know? A content analysis of CME offerings. Journal of Continuing Education in the Health Professions, 35(1), 27-37.

Bray, M., Kehle, T., Lawless, K., \& Theodore, L. (2003). The relationship of selfefficacy and depression to stuttering. American Journal of SpeechLanguage Pathology, 12, 425-431.

Burda, A., \& Hageman, C. (2015). Problem-based learning in speech-language pathology: Format and feedback. Contemporary Issues in Communication Science and Disorders, 42, 47-71.

Cervero, R. \& Gaines, J. (2014). Effectiveness of continuing medical education: Updated syntheses of systematic reviews. Accreditation Council for Continuing Medical Education, Chicago. Retrieved from http//:www.accme.org.

Chisnall, B., Vince, T., Hall, S., \& Tribe, R. (2015). Evaluation of outcomes of a formative objective structured clinical examination for second-year UK medical students. International Journal of Medical Education, 6, 76-83.

David, T. J., Dolmans, D., Patel, L., \& van der Vieuten, C. P. M. (1998). Problembased learning as an alternative to lecture-based continuing medical education. Journal of the Royal Society of Medicine, 91, 626-630.

Davis, D., Thomson O'Brien, M., Freemantle, N., Wolf, F. M., Mazmanian, P., \& Taylor-Vaisey, A. (1999). Import of formal continuing medical education: Do conferences, workshops, rounds, and other traditional continuing 
education activities change physician behavior or health care outcomes? Journal of the American Medical Association, 282(9), 867-874.

Doucet, M., Purdy, R., Kaufman, D., \& Langille, D. (1998). Comparison of problem-based learning and continuing medical education on headache diagnosis and management. Medical Education, 32, 590-596.

Fishbein, M., Flock, S., \& Benton, K. (2013). Self-assessment of pediatric feeding therapists in the state of Illinois. SIG 13 Perspectives on Swallowing and Swallowing Disorders (Dysphagia), 22(4), 129-141.

Fletcher, M. (2007). Continuing education for healthcare professionals: Time to prove its worth. Primary Care Respiratory Journal, 16(3), 188-190.

Forsetlund, L., Bjørndal, A., Rashidian, A., Jamtvedt, G., O’Brien, M. A., Wolf, F., ... \& Oxman, A. D. (2009). Continuing education meetings and workshops: Effects on professional practice and health care outcomes. Cochrane Database of Systematic Reviews, 2, Art. No.: CD003030.

Fyrenius, A., Bergdahl, B., \& Silen, C. (2005). Lectures in problem-based learningWhy, when and how? An example of interactive lecturing that stimulates meaningful learning. Medical Teacher, 27(1), 61-65.

Gibbs, G. (1988). Learning by doing: A guide to teaching and learning methods. London, UK: Federation of Entertainment Unions.

Gordon, M. J. (1991). A review of the validity and accuracy of self-assessments in health professions training. Academic Medicine, 66(12), 762-769.

Harden, R., \& Davis, M. (1998). The continuum of problem-based learning. Medical Teacher, 20(4), 317-322.

Hauer, K.E., Wilkerson, L., \& Teherani, A. (2008). The relationship between medical students' knowledge, confidence, experience, and skills related to colorectal cancer screening. Journal of Cancer Education, 23(4), 209-213.

Ho, D., Whitehill, T., \& Ciocca, V. (2014). Performance of speech-language pathology students in problem-based learning tutorials and in clinical practice. Clinical Linguistics \& Phonetics, 28(1-2), 83-97. 
Houle, C. O. (1984). Patterns of learning: New perspectives on life-span education. San Francisco, CA: Jossey-Bass.

Hess, D. W., Reed, V. A., Turco, M. G., Parboosingh, J. T., \& Bernstein, H. H. (2015). Enhancing provider engagement in practice improvement: A conceptual framework. Journal of Continuing Education in the Health Professions, 35(1), 71-79.

Institute of Medicine (US). Committee on Planning a Continuing Health Care Professional Education Institute. (2010). Redesigning Continuing Education in the Health Professions. National Academies Press.

Kitto, S. C., Bell, M., Goldman J., Peller, J., Silver, I., Sargeant, J., \& Reeves, S. (2013). (Mis) perceptions of continuing education: Insights from knowledge translation, quality improvement, and patient safety leaders. Journal of Continuing Education in the Health Professions, 33(2), 81-88.

Knowles, M. S. (1975). Self-directed learning: A guide for learners and teachers. Englewood Cliffs, NJ: Prentice Hall.

Leach, D. C., \& Fletcher, S. W. (2008). Perspective on continuing education in the health professions: Improving health care through lifelong learning. CHEST Journal, 134(6), 1299-1303.

Mansouri, M., \& Lockyer, J. (2007). A meta-analysis of continuing medical education effectiveness. Journal of Continuing Education in the Health Professions, 27(1), 6-15.

Mavis, B. (2001). Self-efficacy and OSCE performance among second year medical students. Advances in Health Sciences Education, 6, 93-102.

McAllister, A., Aanstoot, J., Hammerstrom, I., Camuelsson, C., Johannesson, E., Sandstrom, K., \& Berglind, U. (2014). Learning in the tutorial group: A balance between individual freedom and institutional control. Clinical Linguistics \& Phonetics, 28(1-2), 28-40.

McCormack, J., McLeod, S., McAllister, L., \& Harrison, L. J. (2010). My speech problem, your listening problem, and my frustration: The experience of living with childhood speech impairment. Language, Speech, and Hearing Services in Schools, 41(4), 379-392. 
Menahem, S., \& Paget, N. (1990). Role play for the clinical tutor: Towards problem-based learning. Medical Teacher, 12, 57-61.

Miller, G. E. (1990). The assessment of clinical skills/competence/performance. Academic Medicine, 65(9), S63- S67.

Mok, C., Whitehill, T., \& Dodd, B. (2008). Problem-based learning, critical thinking and concept mapping in speech-language pathology education: A review. International Journal of Speech-Language Pathology, 10(6), 438448.

O’Donoghue, C., \& Dean-Claytor, A. (2008). Training and self-reported confidence for dysphagia management among speech-language pathologists in the schools. Language, Speech, and Hearing Services in Schools, 39, 192-198.

Opacic, D. (2003). The relationship between self-efficacy and student physician assistant clinical performance. Journal of Allied Health, 32(3), 158-166.

Patricio, M., Juliao, M., Fareleira, F., \& Carneiro, A. (2013). Is the OSCE a feasible tool to assess competencies in undergraduate medical education? Medical Teacher, 35, 503-514.

Prosser, M., \& Sze, D. (2014). Problem-based learning: Student learning experiences and outcomes. Clinical Linguistics \& Phonetics, 28(1-2), 112123.

Rosenthal, R., \& Jacobson, L. (1968). Teacher expectations for the disadvantaged. Scientific American, 218, 19-23.

Rushforth, H. E. (2007). Objective structured clinical examination (OSCE): Review of literature and implications for nursing education. Nurse Education Today, 27(5), 481-490.

Ryan, S., Stevenson, K., \& Hassell, A. (2007). Assessment of clinical nurse specialists in rheumatology using an OSCE. Musculoskeletal Care, 5(3), 119-129.

Salinitri, F., O’Connell, M., Garwood, C., Lehr, V., \& Abdallah, K. (2012). An Objective Structured Clinical Examination to assess problem-based learning. American Journal of Pharmaceutical Education, 76(3), Article 44. 
Sargeant, J., Bruce, D., \& Campbell, C. M. (2013). Practicing physicians' needs for assessment and feedback as part of professional development. Journal of Continuing Education in the Health Professions, 33(1), S54-S62.

Teten, A. F., DeVeney, S. L., \& Friehe, M. J. (2016). Voice disorder management competencies: A survey of school-based speech-language pathologists in Nebraska. Language, Speech, and Hearing Services in Schools, 47(1), 3143.

Wanstall, H. (2010). Objective Structured Clinical Examinations (OSCEs) as predictors of performance on work-based placements. Investigations in University Teaching and Learning, 6, 57-64.

Whitehill, T., Bridges, S., \& Chan, K. (2014). Problem-based learning (PBL) and speech-language pathology: A tutorial. Clinical Linguistics \& Phonetics, $28(1-2), 5-23$.

Zeitz, H. (1999). Problem based learning: Development of a new strategy for effective continuing medical education. Allergy and Asthma Proceedings, 20(5), 317-321.

\section{Appendix A}

\section{Example of case study presentation and probing/guiding questions for discussion}

Case History: AL (DOB: XX/XX/09) was initially evaluated at 2 years, 6 months old. He had four words and a history of 5-6 ear infections. He lives in a supportive home with both parents.

Assessment: Preschool Language Scale Receptive Language (2yrs; 6m) (standard score $=92$, percentile rank $=30$ ); Expressive Language (standard score $=61$, percentile rank $=1$ ). Strengths: producing consonants $/ \mathrm{n}, \mathrm{m}, \mathrm{d}, \mathrm{b} /$; extending a toy or pointing to an object to show a need. Weaknesses: does not imitate words; uses vocalizations \& gestures to request toys and food; babbles short syllable strings. His primary mode of communication is to take a person to the object of choice. Minimal vocalizations have been noted, but the client does participate in social routines. Therapy was suggested for 2 sessions/week. Referrals were made to occupational therapy and audiology. 
Initial therapy goals focused on turn-taking, use of vocalizations and gestures to request, imitation of CVC vocalizations, and family education. The client made general progress for 6 months, but with minimal variety of sounds in vocalizations. No progress with CVC productions.

At age 3, the Kaufman Speech Praxis Test revealed a standard score < 30, percentile rank of $<4$ compared to same age "disordered" children. Therapy was recommended for 4 - 5 sessions per week. The audiology evaluation showed normal results and he received OT $2 x /$ week.

These additional assessments were administered:

- Kaufman Speech Praxis Test $(2 \mathrm{ys} ; 10 \mathrm{~m})$. Difficulty with oral movement for: lateralize tongue left, alternate tongue lateralization, elevate tongue to alveolar ridge, pucker lips, alternate spread/pucker. Most pure vowels were produced, poor vowel to vowel movement, substituted $\mathrm{t} / \mathrm{d}, \mathrm{m} / \mathrm{n}$, could repeat $\mathrm{CVCV}$, difficulty with $\mathrm{CV}, \mathrm{VCV}, \mathrm{CVCV} 2, \mathrm{CVC}, \mathrm{C}$, and unable to produce any CVC2V2 correctly.

- Receptive One Word Picture Vocabulary Test (2ys;11m). Standard score = 112, Percentile rank $=83$

- Goldman Fristoe Test of Articulation 2 (3yrs;11m). Standard score $=58$, Percentile rank $=1$. Client demonstrated final consonant deletion, consonant cluster reduction, stopping of fricatives, assimilation, pre-vocalic fronting. Intelligibility in conversation without context was poor.

- Oral Written Language Scales-II (3yrs;11m). Listening Comprehension: Standard score $=109$, Percentile rank $=75$. Oral Expression: Standard score $=$ 96, Percentile rank $=37$.

- Goldman Fristoe Test of Articulation 2 (4 yrs; $11 \mathrm{~m}$ ). Standard score $=49$, Percentile rank $=<1$. Client continued to demonstrate final consonant deletion, consonant cluster reduction and stopping fricatives, but velars emerging in initial position. Intelligibility without context is fair.

Summary at age 5 years: little progress toward his goals the last 6 months.

Examples of probing/guiding questions by Instructors:

- Is the diagnosis of CAS correct? Explain your answer.

- What informal assessments are needed to establish a CAS diagnosis?

- What treatment goals should be established for the next 6 months? What rationale(s) supports each goals?

- What sounds and syllable structures should be targeted in treatment and why? 


\section{Appendix B}

\begin{tabular}{|c|c|c|c|c|}
\hline \multicolumn{5}{|c|}{ Alternative Objective Structured Clinical Exam Rubric } \\
\hline $\begin{array}{l}\text { Name: } \\
\text { Date: } \\
\text { Participant \#: }\end{array}$ & $\begin{array}{l}\text { Self-Assessment } \\
\text { Before Boot Camp } \square \\
\text { End of Boot Camp } \square \\
\text { Final Case Study } \square\end{array}$ & \multicolumn{3}{|c|}{$\begin{array}{l}\text { Instructor Assessment } \\
\text { End of Boot Camp } \square \\
\text { Final Case Study } \square\end{array}$} \\
\hline \multicolumn{5}{|c|}{$\begin{array}{l}\text { Instructor Key: } 1=\text { very poor, } 2=\text { poor, } 3=\text { good, } 4=\text { very good, } 5=\text { excellent } \\
\text { Clinician Key: } 1=\text { not at all confident, } 2=\text { somewhat confident, } 3=\text { confident, } 4 \\
=\text { very confident, } 5=\text { extremely confident }\end{array}$} \\
\hline \multirow{2}{*}{\multicolumn{5}{|c|}{$\begin{array}{l}\text { Instructors: Please check the appropriate box marked "Instructor." Below is } \\
\text { a rubric detailing aspects of clinical competency. To the best of your ability, please } \\
\text { rate your current perception of the clinician's clinical skills in relation to the } \\
\text { following skill set. } \\
\text { Clinicians: Please check the appropriate box marked "Self-Assessment." } \\
\text { Below is a rubric detailing aspects of clinical competency. To the best of your } \\
\text { ability, please rate your current perception of your clinical skills in relation to the } \\
\text { following skill set. }\end{array}$}} \\
\hline & & & & \\
\hline \multicolumn{3}{|l|}{ Assessment } & Rating & \\
\hline \multicolumn{3}{|c|}{$\begin{array}{l}\text { Collects and integrates pertinent case history } \\
\text { information }\end{array}$} & 123 & \\
\hline \multicolumn{3}{|c|}{$\begin{array}{l}\text { Selects, develops, and uses appropriate } \\
\text { materials and instrumentation during evaluation } \\
\text { procedures }\end{array}$} & 4 & \\
\hline \multicolumn{3}{|c|}{$\begin{array}{l}\text { Adapts evaluation procedures to elicit target } \\
\text { speech and suprasegmental features }\end{array}$} & 45 & \\
\hline \multicolumn{3}{|c|}{$\begin{array}{l}\text { Exercises clinical judgment to establish a } \\
\text { diagnosis, taking into account physical, } \\
\text { psychological, and social factors }\end{array}$} & 4 & \\
\hline \multicolumn{3}{|c|}{$\begin{array}{l}\text { Differentially diagnoses CAS from other SSDs } \\
\text { and dysarthria }\end{array}$} & 123 & \\
\hline \multicolumn{3}{|c|}{$\begin{array}{l}\text { Identifies levels of breakdown in speech } \\
\text { precision (e.g., isolation, complexity of syllable } \\
\text { shape, word length, familiarity or novelty) }\end{array}$} & 123 & \\
\hline \multicolumn{3}{|c|}{$\begin{array}{l}\text { Conducts stimulability testing in areas of } \\
\text { breakdown }\end{array}$} & 123 & \\
\hline
\end{tabular}




\begin{tabular}{|l|lllll|l|}
\hline $\begin{array}{l}\text { Distinguishes between age-appropriate } \\
\text { articulatory errors and disordered errors }\end{array}$ & 1 & 2 & 3 & 4 & 5 & \\
\hline $\begin{array}{l}\text { Evaluates performance across multiple contexts } \\
\text { (spontaneous, elicited, imitation) }\end{array}$ & 1 & 2 & 3 & 4 & 5 & \\
\hline $\begin{array}{l}\text { Identifies contexts of accurate production (e.g., } \\
\text { vowel environment, word position, syllable } \\
\text { structure) }\end{array}$ & 1 & 2 & 3 & 4 & 5 & \\
\hline $\begin{array}{l}\text { Conducts evaluation of child's verbal imitative } \\
\text { skills (e.g., repetitions of same stimuli vs. } \\
\text { repetitions of varying stimuli) }\end{array}$ & 1 & 2 & 3 & 4 & 5 & \\
\hline $\begin{array}{l}\text { Identifies cues needed for accuracy (e.g., tactile, } \\
\text { visual, auditory, or combination) }\end{array}$ & 1 & 2 & 3 & 4 & 5 & \\
\hline Considers prosody of utterance & 1 & 2 & 3 & 4 & 5 & \\
\hline Considers smoothness of articulatory transitions & & & & & & \\
\hline $\begin{array}{l}\text { Evaluates automatic speech (e.g., reciting } \\
\text { alphabet, counting) vs. volitional movement } \\
\text { (e.g., imitation of movement, movement or } \\
\text { speech on command) }\end{array}$ & 1 & 2 & 3 & 4 & 5 & \\
\hline $\begin{array}{l}\text { Analyzes consonant and vowel phonetic } \\
\text { inventory }\end{array}$ & 1 & 2 & 3 & 4 & 5 & \\
\hline $\begin{array}{l}\text { Analyzes consonant and vowel phonemic } \\
\text { inventory }\end{array}$ & & & & & & \\
\hline Analyzes syllable shapes & 1 & 2 & 3 & 4 & 5 & \\
\hline $\begin{array}{l}\text { Utilizes external resources (e.g., research, } \\
\text { pertinent literature, expert opinion) when } \\
\text { necessary during evaluation procedures }\end{array}$ & 1 & 2 & 3 & 4 & 5 & \\
\hline Intervention & 1 & 2 & 3 & 4 & 5 & \\
\hline $\begin{array}{l}\text { Develops or modifies appropriate intervention } \\
\text { plans that address stimulability with measurable } \\
\text { and achievable goals }\end{array}$ & 1 & 2 & 3 & 4 & 5 & \\
\hline $\begin{array}{l}\text { Identifies and uses available resources in } \\
\text { developing a treatment plan }\end{array}$ & 1 & 2 & 3 & 4 & 5 & \\
\hline $\begin{array}{l}\text { Selects targets based upon current phonemic or } \\
\text { phonetic repertoire with addition of new } \\
\text { movement(s) }\end{array}$ & 1 & 2 & 3 & 4 & 5 & \\
\hline $\begin{array}{l}\text { Selects targets in therapy to build a functional } \\
\text { core vocabulary }\end{array}$ & 1 & 2 & 3 & 4 & 5 & \\
\hline $\begin{array}{l}\text { Understands factors associated with appropriate } \\
\text { target selection (e.g., homorganic sound } \\
\text { selection, targeting salient words, including }\end{array}$ & 1 & 2 & 3 & 4 & 5 & \\
\hline
\end{tabular}




\begin{tabular}{|c|c|c|c|c|c|c|}
\hline $\begin{array}{l}\text { "power" words) and matching to the available } \\
\text { repertoire }\end{array}$ & & & & & & \\
\hline $\begin{array}{l}\text { Selects, develops, and uses appropriate } \\
\text { motivating materials and instrumentation for } \\
\text { intervention with opportunities for optimal } \\
\text { repetition }\end{array}$ & & 2 & 23 & 4 & & \\
\hline $\begin{array}{l}\text { Utilizes external resources (e.g., research, } \\
\text { pertinent literature, expert opinion) when } \\
\text { necessary during course of intervention }\end{array}$ & & & ?. & 4 & 5 & \\
\hline $\begin{array}{l}\text { Provides client specific feedback appropriate for } \\
\text { client skill level }\end{array}$ & & 2 & . & 4 & & \\
\hline $\begin{array}{l}\text { Refers to and integrates existing treatment } \\
\text { efficacy literature into treatment session }\end{array}$ & & 2 & 2 & 4 & 5 & \\
\hline $\begin{array}{l}\text { Self-evaluates efficacy of treatment plan and } \\
\text { adjusts accordingly }\end{array}$ & & & & & & \\
\hline $\begin{array}{l}\text { Recognizes the client's individual needs by } \\
\text { observing levels of attention, interaction, and } \\
\text { enthusiasm and adjusting therapy accordingly }\end{array}$ & 1 & 2 & . & 4 & 5 & \\
\hline $\begin{array}{l}\text { Involves cognitive motor learning during } \\
\text { repetitive practice (e.g., client understands task, } \\
\text { client is engaged) }\end{array}$ & & 2 & 3 & 4 & & \\
\hline $\begin{array}{l}\text { Fades cues and moves through cueing hierarchy } \\
\text { (i.e., simultaneous, direct imitation, delayed } \\
\text { imitation, spontaneous) }\end{array}$ & & 3 & i & 4 & & \\
\hline Integration/Other & & & & & & \\
\hline $\begin{array}{l}\text { Has general knowledge in the etiology, } \\
\text { evaluation, and treatment of CAS }\end{array}$ & & 2 & . & 4 & & \\
\hline $\begin{array}{l}\text { Demonstrates self-confidence in clinical skills } \\
\text { in the treatment of CAS }\end{array}$ & & 3 & 2 & 4 & & \\
\hline Displays self-direction and flexibility & 1 & 2 & 2 & 4 & 5 & \\
\hline $\begin{array}{l}\text { Manages clients in an effective, efficient, and } \\
\text { ethical manner }\end{array}$ & & 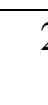 & 2 & 4 & & \\
\hline $\begin{array}{l}\text { Collaborates with other professionals in case } \\
\text { management }\end{array}$ & & 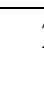 & 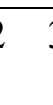 & 4 & & \\
\hline Refers clients for appropriate services & & ( & 2 & 4 & & \\
\hline $\begin{array}{l}\text { Provides counseling regarding CAS to family } \\
\text { and caregivers }\end{array}$ & & 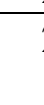 & 2 & 4 & & \\
\hline $\begin{array}{l}\text { Teaches client's family members about the } \\
\text { client's needs }\end{array}$ & & 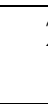 & 2 & 4 & & \\
\hline
\end{tabular}


Teaching and Learning in Communication Sciences \& Disorders, Vol. 2 [2018], Iss. 1, Art. 1

\begin{tabular}{|l|lllll|l|}
\hline $\begin{array}{l}\text { Explains evaluation or therapy procedures to } \\
\text { family members prior to performing them }\end{array}$ & 1 & 2 & 3 & 4 & 5 & \\
\hline Seeks assistance when necessary & 1 & 2 & 3 & 4 & 5 & \\
\hline Remains open to the suggestions of colleagues & 1 & 2 & 3 & 4 & 5 & \\
\hline $\begin{array}{l}\text { Awareness of learning opportunities for ongoing } \\
\text { personal and professional growth }\end{array}$ & 1 & 2 & 3 & 4 & 5 & \\
\hline Comments: & & & & & \\
\hline
\end{tabular}

